\title{
Halte au pillage !
}

\section{Vincent Carpentier}

\section{CpenEdition}

\author{
Journals
}

Édition électronique

URL : http://journals.openedition.org/rao/1476

DOI : 10.4000/rao.1476

ISBN : 978-2-7535-1846-9

ISSN : 1775-3732

Éditeur

Presses universitaires de Rennes

Édition imprimée

Date de publication : 31 décembre 2011

Pagination : 290-291

ISBN : 978-2-7535-1844-5

ISSN : 0767-709X

\section{Référence électronique}

Vincent Carpentier, « Halte au pillage ! », Revue archéologique de l'Ouest [En ligne], 28 | 2011, mis en

ligne le 30 mars 2012, consulté le 06 décembre 2020. URL : http://journals.openedition.org/rao/1476 DOI : https://doi.org/10.4000/rao.1476

Ce document a été généré automatiquement le 6 décembre 2020.

Tous droits réservés 


\title{
Halte au pillage !
}

\author{
Vincent Carpentier
}

\section{RÉFÉRENCE}

Compagnon, G., 2010 - Halte au pillage !, Paris, Errance, coll. « Les Hespérides », 446 p.

(ISBN 978-2-87772-433-3, $32 €$ )

1 Cet ouvrage collectif, dirigé par Grégory Compagnon, président de l'association « Halte au pillage du patrimoine archéologique et historique » (HAPPAH), fait le point sur le pillage des ressources archéologiques, un phénomène mondial qui, parce qu'il est doté de moyens considérables et à l'origine de fortunes tout aussi considérables, a pris depuis le milieu du $\mathrm{xx}^{\mathrm{e}}$ siècle une ampleur sans précédent. Fouilles clandestines, usage illégal du détecteur de métaux, trafic mondialisé des antiquités, ont entraîné la disparition de pans entiers du patrimoine de l'Humanité, laissant certaines régions du monde définitivement privées de mémoire. En France, au Cameroun, dans le Sahara, en Polynésie ou en Alaska, l'archéologue, une fois disparus les « beaux » objets, se retrouve ainsi comme devant un livre d'histoire de l'art dont toutes les illustrations auraient été découpées et dispersées. Les communications réunies dans ce livre utile et dense, montrent qu'il existe une géographie du pillage, parée d'une inégalité flagrante puisque ce phénomène atteint surtout les pays les plus pauvres. Activité illégale mais extrêmement lucrative, aux mains de réseaux organisés à l'échelle planétaire, le pillage s'affiche aujourd'hui sur tous les sites de vente par internet. En réponse à l'urgence de la situation, Grégory Compagnon et son association se proposent d'alerter le public sur la réalité de cette destruction de la mémoire collective, pour aller au-delà d'un arsenal juridique qui, dans les faits, s'avère impuissant à enrayer le fléau, et aussi informer sur ce que sont réellement l'archéologie et l'ethnologie. Car l'archéologie est en effet bien différente aujourd'hui du pillage : elle étudie l'objet en tant que source d'informative dans son contexte, révélant ainsi les héritages du passé, sans se contenter d'accumuler les objets pour eux-mêmes, en de stériles collections. Aussi un objet pillé est-il sans valeur aux yeux de l'archéologue, parce que dépourvu du lien qui l'unit au passé. Préserver ce lien, en conserver la trace, relève d'une méthode exigeante et d'un enjeu 
collectif, celui de la mémoire, en vertu duquel, dans les faits, l'objet archéologique est protégé par le législateur. Or, le pilleur brave la loi et méprise l'intérêt collectif. En conscience, il commet un acte de violence contre le bien commun, en violant le contenant pour s'emparer du contenu, dans le but premier, et bien souvent non avoué, de s'enrichir.

2 Le pillage s'inscrit également dans un processus historique. Ses premières manifestations remontent peut-être à l'âge du Bronze, avec le viol de tombes, en Asie centrale, dans le but d'y récupérer des objets en métal précieux. En Europe, le phénomène connaît un essor notable au cours des XVIII ${ }^{\mathrm{e}}$-XIX ${ }^{\mathrm{e}}$ siècles, qui aboutit, au milieu du $\mathrm{XX}^{\mathrm{e}}$ siècle, à la séparation entre d'une part les archéologues scientifiques, et d'autre part les collectionneurs amateurs d'art dont les pratiques glissent vers l'illégalité. Depuis les années 1960, l'arme par excellence des pilleurs européens est le détecteur de métaux, véritable fléau du patrimoine archéologique, de telle sorte qu'aujourd'hui, le milieu des archéologues « autorisés » se retrouve en guerre contre le microcosme disparate des pilleurs de tout crin. Il existe, aux côtés d'archéologues amateurs auto déclarés, d'authentiques professionnels du pillage à travers le monde : tombaroli italiens, huaqueros péruviens, esteleros guatémaltèques, clandestini siciliens... Les modalités de leur métier sont plurielles, tantôt nées de la misère, tantôt de la curiosité, de l'ésotérisme parfois, de la cupidité souvent. Les moyens mis en œuvre sont de plus en plus importants et destructeurs; outre le détecteur, certains pilleurs n'hésitent pas à faire usage de la dynamite, de bulldozers ou de scies électriques pour parvenir à leurs fins. Parfois, des trafics nauséabonds ou le terrorisme se dissimulent derrière le pillage des sites archéologiques, car les sommes en jeu sont considérables, d'autant plus quand il s'agit de populations démunies qui, au final, ne reçoivent guère plus de 1 à $2 \%$ de la valeur marchande de leurs découvertes.

3 En Europe, des nuances se dessinent entre l'ouest et l'est, en fonction des niveaux de vie et de l'organisation souterraine du marché parallèle des objets archéologiques. Les grottes et leurs fossiles, les ruines antiques, les champs de bataille et jusqu'aux restes des soldats tombés au combat, tous protégés par la loi, y sont la cible de plus en plus fréquente de pilleurs dont la recrudescence pourrait trouver son origine dans le déclin récent de l'archéologie bénévole. Ceci n'atténue en rien le scandale que constitue l'utilisation des détecteurs de métaux, un hobby largement répandu qui viole pourtant, sans ambiguïté, la législation, notamment française. Face à ce péril grandissant, certains archéologues envisagent, en Angleterre notamment, de coopérer avec les détecteurs, mais le bilan de ces expériences s'avère globalement négatif, le compromis débouchant généralement sur une incitation à des pratiques contraires aux principes de la protection légale du patrimoine. Tristesse, mythomanie et mauvaise foi forment le cortège de cette " archéologie noire » qui préside, à travers l'Europe, au saccage d'un patrimoine-ressource dont on commence tout juste à prendre conscience aujourd'hui qu'il n'est pas, lui non plus, illimité.

4 La situation internationale est franchement préoccupante. Dans certaines parties des Amériques, comme au Pérou, plus de $90 \%$ du patrimoine a disparu du fait des pilleurs. La mise en place d'outils pertinents, comme les SIG, permettent aujourd'hui d'informer les décideurs sur cette activité illégale et les réseaux qui la dirigent. Dans d'autres régions du globe, en Afrique, en Polynésie, le pillage est pour ainsi dire institutionnalisé depuis l'ère coloniale. L'essor du tourisme, au XXe siècle, n'a fait qu'aggraver les choses; intrusion de la modernité dont la première conséquence est la disparition de 
toutes les traces laissées par la préhistoire, y compris dans des zones jusqu'alors plus ou moins inexplorées.

Quelques solutions s'esquissent, dans ce contexte pessimiste, grâce d'abord à l'action du législateur. L'appareil législatif constitue la première sinon la seule réponse adaptée des sociétés au fléau du pillage. Il est aujourd'hui le produit d'une évolution remarquable, depuis la Convention de La Haye (1954) jusqu'à celles de 1992 et 2001. Toutefois, les situations comme les modalités d'application de la loi restent fort inégales d'un continent et d'un pays à l'autre. Pour autant, la recherche d'un consensus entre archéologues scientifiques et pilleurs-collectionneurs achoppe inévitablement sur la valeur exceptionnelle reconnue à certains objets, au détriment de leur contexte tout entier qui est pourtant le vecteur authentique de la mémoire. Le pillage du passé de l'Humanité se poursuit donc, sur un rythme bien inquiétant, sans que l'on sache au juste comment y mettre un frein. À bien des égards, cette alerte au pillage proposée par l'ouvrage de Grégory Compagnon, fait écho à l'actualité environnementale et interpelle le lecteur, après lui avoir livré un minutieux et accablant état des lieux, sur une authentique urgence, un devoir de mémoire et de citoyenneté qui concerne tout un chacun, membre de la grande communauté du village-monde. 